\title{
Characterization and Cell Distribution of Polycystin, the Product of Autosomal Dominant Polycystic Kidney Disease Gene 1
}

\author{
Runolfur Palsson, ${ }^{* \dagger}$ Chander P. Sharma, ${ }^{* \dagger}$ Keetae Kim, ${ }^{* \dagger}$ \\ Margaret McLaughlin, Dennis Brown, ${ }^{* \neq}$ \\ and $M$. Amin Arnaout* ${ }^{\star}$ \\ Leukocyte Biology and Inflammation Program, *Renal Unit and \\ Departments of ${ }^{\dagger}$ Medicine and ${ }^{\ddagger}$ Pathology, Massachusetts General \\ Hospital and Harvard Medical School, Boston, Massachusetts, U.S.A.
}

\begin{abstract}
Background: In a majority of cases, autosomal dominant polycystic kidney disease (ADPKD) is caused by mutations within a putative open reading frame of the PKD 1 gene. The encoded protein, polycystin, is predicted to span the plasma membrane several times and contains extracellular domains, suggestive of a role in cell adhesion. The cellular distribution and function of polycystin is not known.

Materials and Methods: We selected as immunogens two conserved 15 amino acid peptides: $\mathrm{Pl}$, located in a predicted extracellular region of polycystin, and P2, located in the C-terminal putative cytoplasmic tail. The anti-peptide antibodies from immunized rabbits were affinity purified on peptide-coupled resins and their specificity confirmed by their selective binding to recombinant polycystin fusion proteins. Western blotting and immunohistochemistry were used to characterize the size, tissue, and cell distribution of polycystin.

Results: A high-molecular mass protein (about 642 kD)
\end{abstract}

was detected by Western blotting in rat brain tissue. A few additional bands, in the 100- to $400-\mathrm{kD}$ range, probably representing tissue-specific variants and/or proteolytic fragments, were recognized in human and rat tissues. Polycystin was abundantly expressed in fetal kidney epithelia, where it displayed basolateral and apical membrane distribution in epithelial cells of the ureteric buds, collecting ducts, and glomeruli. In normal human adult kidney, polycystin was detected at moderate levels and in a cell surface-associated distribution in cortical collecting ducts and glomerular visceral epithelium. Expression of polycystin was significantly increased in cyst-lining epithelium in ADPKD kidneys, but was primarily intracellular.

Conclusions: Polycystin appears to be a developmentally regulated and membrane-associated glycoprotein. Its intracellular localization in the cyst-lining epithelium of $\mathrm{ADPKD}$ kidneys suggests an abnormality in protein sorting in this disease.

\section{INTRODUCTION}

Autosomal dominant polycystic kidney disease (ADPKD) is one of the most common genetic diseases in humans (1). With an estimated incidence of 1 in 1000 individuals, ADPKD is the most common genetic cause of renal failure, accounting for $8-10 \%$ of end-stage renal disease (2). The characteristic feature of this disease is

Address correspondence and reprint requests to: $\mathrm{M}$. Amin Arnaout, Renal Unit, Massachusetts General Hospital, 149 and 13th Street, Charlestown, MA 02129, U.S.A. the formation and progressive enlargement of multiple fluid-filled cysts in both kidneys, often resulting in massive kidney enlargement. The enlarging cysts gradually cause destruction of normal renal parenchyma, leading to impaired function, with end-stage renal failure occurring in $50 \%$ of affected individuals by the age of 60 (3). Although renal involvement is the hallmark of ADPKD, extrarenal manifestations are very common and include cysts in various organs, cardiac valve defects, intracranial aneurysms, colonic diverticulae, and inguinal hernias. 
ADPKD has been linked to three different loci: PKD1 on chromosome 16 (4), PKD2 on chromosome $4(5,6)$, and a yet to be mapped PKD3 $(7,8)$. Mutations in PKDl account for about $85-95 \%$ of patients suffering from ADPKD and generally cause the more severe form, with an earlier onset of end-stage renal disease $(3,9)$. Human PKDl was identified by positional cloning, and homologs have been found in rodents, fish, and worm (Refs. 10 and 11, and our unpublished observations). PKDl transcripts have been found in many tissues including human brain, liver, kidney, and colon $(12,13)$. Mutations in the $3^{\prime}$ region of human PKDl were detected in several patients with ADPKD $(12,14,15)$. In humans, but apparently not in rodents, approximately $50 \mathrm{~kb}$ of DNA, including all but about 10 $\mathrm{kb}$ of the $3^{\prime}$ region of PKDl is duplicated with $>95 \%$ sequence homology, centromeric to PKD l (12). The duplicated area contains at least four copies of the PKDl region, encoding three homologous genes, and although these are transcribed, it is not currently known if functional protein(s) are produced.

The protein encoded by the bona fide human PKD 1 transcript, polycystin, is $4302 / 3$ amino acids (aa) in length, with 60 potential $\mathrm{N}$-glycosylation sites $(14,15)$. It is a putative multispanning membrane protein with a large $\mathrm{N}$-terminal ectodomain containing a unique compilation of known cell adhesion domains. These include two leucine-rich repeats, a C-type lectin domain, and 16 immunoglobulin-like domains. Despite these recognized features, the size and function of this protein are unknown. The biochemical defect(s) that triggers renal cyst formation in ADPKD and the mechanism(s) responsible for its autosomal dominant inheritance are also unknown. Abnormal thickening and disorganization of the tubular basement membrane noted in the early stages of the disease (16), together with evidence of epithelial dedifferentiation at focal areas of tubular dilatation $(17,18)$, suggest a potential role of polycystin in cell and matrix adhesion.

In this report, we determined the molecular mass of polycystin and its localization in normal and diseased tissues using anti-peptide antibodies that also cross-react with the rat protein. Multiple forms of the protein were detected by Western blotting; in particular, one form with a high molecular mass, of $642 \mathrm{kD}$, was detected in rat brain. In normal fetal and adult kidney epithelium, polycystin exhibits basolateral and apical cell distributions. In contrast, polycystin was located intracellularly in ADPKD cystic kidney epithelium, suggesting a defect in protein trafficking and a potential mechanism by which PKD l mutations cause disease.

\section{MATERIALS AND METHODS}

\section{Generation of Anti-Polycystin Antibodies}

$\mathrm{P} 1$ and P2, 15 aa peptides from the predicted sequence of human polycystin, were synthesized. Both peptides were selected based on their hydrophilicity, surface probability, and antigenicity using the PeptideStructure Program from the Genetics Computer Group, Inc. (GCG, Madison, WI, U.S.A.). In addition, they were poor in serines and threonines, and hence less likely to be masked by carbohydrate chains. P1 and P2 were outside the regions of recognized motifs and had no homologs in the GenBank protein databases. Human P1 (GEEIVAQGKRSDPRS, equivalent to GEEIVALGKRSDPLS in the mouse [A.-M. Frischauf, personal communication]) is contained within the duplicated region of the gene. P2 (LSKVKEFRHKVRFEG, equivalent to FSKVKEFRHKVRFEG in the mouse [K. Kim and M. A. Arnaout, unpublished]) was derived from the 3' single copy region, encoding the putative cytoplasmic C-terminal portion of polycystin. Each of the purified peptides were coupled through a synthetic $\mathrm{N}$-terminal cysteine to keyhole limpet hemicyanin (KLH) and bovine serum albumin (BSA). Two New Zealand white rabbits were immunized with the KLH-coupled peptides. The immune sera reacted strongly by enzyme-linked immunosorbent assay (ELISA) with the respective BSA-coupled peptides (not shown). Anti-peptide antibodies were purified using affinity columns prepared by coupling each peptide to SulfoLink affinity resin (Pierce Chemical Co., Rockford, IL, U.S.A.). Each affinity-purified antibody reacted specifically with its respective BSA-coupled peptide (not shown). Protein concentrations were estimated by measuring absorbance at $280 \mathrm{~nm}$.

\section{Expression of Recombinant Polycystin Peptides}

The cDNAs $3 A 3$ (12) and FK7 (14) were gifts from Dr. Peter C. Harris (Oxford, United Kingdom) and Dr. M. Alexandra Glucksmann-Kuis (Millennium Pharmaceuticals, Cambridge, MA, U.S.A.), respectively. The $3 A 3$ cDNA was digested with the restriction endonucleases FspIEcoRI, releasing a 527 bp fragment, which was 
cloned in frame into the BamHI-EcoRI-restricted expression vector pRSETA (Invitrogen, San Diego, CA), to generate an oligohis-tagged fusion protein containing aa 4135-4302 of human polycystin. An 851-bp SacI-BamH-restricted fragment from cDNA clone FK7 was also cloned in frame into $P v u I I-$ restricted pRSETA, to generate a fusion protein containing aa 2678-2960 of human polycystin. The correct orientations of the cDNA inserts were confirmed by restriction analysis and DNA sequencing. Each plasmid was transformed into the Escherichia coli strain BL21 (DE3) (Novagen, Madison, WI, U.S.A.). E. coli were cultured in LB medium followed by induction with Isopropylthiogalactopyranoside (IPTG) at $0.2 \mathrm{mM}$ for $3 \mathrm{hr}$ at $37^{\circ} \mathrm{C}$. The cellular proteins were harvested and analyzed by SDS-PAGE, Coomassie staining, and Western blotting.

\section{Tissue Specimens}

Rat fetal and adult tissues were obtained from pregnant Sprague-Dawley rats (Sprague-Dawley Inc., Indianapolis, IN, U.S.A.) at 18 days of gestation using a protocol approved by the Massachusetts General Hospital (MGH) Animal Care subcommittee, immediately frozen in liquid nitrogen, and stored at $-80^{\circ} \mathrm{C}$ until used. Fresh normal human adult kidney tissue was obtained from the National Disease Research Interchange (Philadelphia, PA, U.S.A.), under protocols approved by the MGH Human Subjects subcommittee. The kidney tissue was immediately frozen in liquid nitrogen and stored at $-80^{\circ} \mathrm{C}$ until used. Fresh normal human fetal kidneys were obtained from human fetuses that were legally aborted at 12 and 20 weeks of gestation. Fetal kidneys were either placed in $10 \%$ formalin for fixation or immediately frozen in liquid nitrogen and stored at $-80^{\circ} \mathrm{C}$ until used. Fresh kidney tissues from two patients with ADPKD and endstage renal disease who underwent nephrectomy were obtained through the PKD Foundation. Slides containing 4-mm sections of formalinfixed, paraffin-embedded normal kidney tissues from adults who underwent nephrectomy for renal cell carcinoma were obtained from the MGH Department of Pathology.

\section{Western Blotting}

To assess the specificity of the affinity-purified anti-peptide antibodies, E. coli expressing the polycystin-derived fusion proteins were solubilized in $1 \times$ Laemmli sample buffer and electrophoresed on
$14 \%$ SDS-PAGE, followed by electroblotting onto an Immobilon-P membrane (Millipore, Bedford, MA, U.S.A.). The membrane was blocked with $10 \%$ dried nonfat milk in phosphate-buffered saline (PBS) containing $0.1 \%$ Tween-20 (PBS-T), followed by incubation with affinity-purified antipeptide antibodies (at $5 \mu \mathrm{g} / \mathrm{ml}$ ). The membrane was washed, incubated with a secondary horseradish peroxidase-conjugated goat anti-rabbit antibody (Sigma Chemical Co., St. Louis, MO), washed again, and developed by enhanced chemiluminescence (ECL system; Amersham Corporation, Arlington Heights, IL, U.S.A.).

Western blotting of rat tissues was carried out as follows: forty $10-\mathrm{mm}$ sections of freshly frozen adult brain tissue and of sagittal hemisections of fetuses across kidney tissue were cut in a cryostat and solubilized in $1 \mathrm{ml}$ of Laemmli sample buffer (19). Proteins were separated by electrophoresis on a 3-11\% gradient SDS-PAGE under reducing conditions, then electroblotted onto Immobilon-P membrane (Millipore). Freshly frozen human fetal kidney tissues were homogenized with a Dounce tissue homogenizer in icecold lysis buffer $(50 \mathrm{mM}$ Tris- $\mathrm{HCl} \mathrm{pH} 7.4,110$ $\mathrm{mM} \mathrm{NaCl}, 1 \%$ Triton X-100, 5 mM EDTA, 0.5 mM Na-orthovanadate, $5 \mathrm{mM}$ diisopropylfluorophosphate, $1 \mathrm{mM}$ phenylmethylsulfonylfluoride, $2 \mathrm{mg} / \mathrm{ml}$ pepstatin, and Complete proteinase inhibitors; Boehringer-Mannheim, Indianapolis, IN, U.S.A.). The homogenate was incubated on ice for $10 \mathrm{~min}$ followed by centrifugation at $10,000 \mathrm{rpm}$ in a Beckmann minicentrifuge at $4^{\circ} \mathrm{C}$. The soluble proteins were separated in a 3-11\% gradient SDS-PAGE under reducing conditions and then electroblotted. The Immobilon-P membranes were blocked, then incubated with anti-peptide antibodies (each at $5 \mu \mathrm{g} / \mathrm{ml}$ ) for $1 \mathrm{hr}$ at room temperature in the presence or absence of the corresponding immunization peptide (at a 10 -fold molar excess). Membranes were then processed as described above.

\section{Immunohistochemistry}

Freshly frozen and fixed tissues were cut, respectively, into 5- and 4-mm sections and mounted on Superfrost/Plus microscope slides (Fisher Scientific, Pittsburgh, PA, U.S.A.). Immunostaining of cryosections was performed using affinitypurified anti-peptide antibodies. Tissue sections were blocked with $1 \%$ BSA in PBS for 20 min at room temperature. Afterwards, the sections were incubated with each antibody (at $5-10 \mu \mathrm{g} / \mathrm{ml}$ in $1 \% \mathrm{BSA}$ ) for $\mathrm{l} \mathrm{hr}$ at room temperature or over- 
night at $4^{\circ} \mathrm{C}$, in the absence or presence of a 10 -fold molar excess of the corresponding peptide. To expose the "hidden" putative cytoplasmic epitope, the frozen sections were fixed by incubation in $95 \%$ ethanol at $4^{\circ} \mathrm{C}$ for $5 \mathrm{~min}$ and subsequently denatured by incubation in $6 \mathrm{M}$ urea/0.1 M glycine, $\mathrm{pH} \mathrm{3.5,} \mathrm{for} 1 \mathrm{hr}$ at $4^{\circ} \mathrm{C}(20)$. Sections were then blocked with $1 \%$ BSA, followed by addition of the primary antibodies. Sections of fresh human adult kidney tissue were stained with an antibody directed against the 56 $\mathrm{kD}$ subunit of $\mathrm{H}^{+}$-ATPase (at 1:100 dilution) (21), then processed as described above for API. Sections of human adult and fetal kidney tissue were additionally stained (for $30 \mathrm{~min}$ at RT) with FITCconjugated Dolichos biflorus agglutinin (DBA) to identify kidney collecting ducts (22). Sections of formalin-fixed paraffin-embedded tissue were dewaxed by incubation in Xylenes. The tissue was subsequently rehydrated by serial incubations in ethanol of decreasing concentrations. The tissue was blocked with BSA, then incubated for $\mathrm{l} \mathrm{hr}$ each with the primary antibodies and a 1:800 dilution of a CY3-conjugated goat anti-rabbit IgG secondary antibody (Jackson ImmunoResearch Laboratories, Inc., West Grove, PA, U.S.A.). The sections were then mounted in Vectashield mounting medium (Vector Laboratories, Inc., Burlingame, CA, U.S.A.). Slides were examined by Nikon FXA epifluorescence microscope and BioRad MRC600 laser confocal microscope. Photographs were taken on Kodak Tmax-400 film, 1600 ASA.

\section{RESULTS}

\section{Characterization of Anti-Polycystin Antibodies}

The ability of each affinity-purified antibody to detect the respective peptide in the context of a large fragment of polycystin was determined using Western blotting of recombinant polycystinderived fusion proteins. As shown in Fig. 1, each antibody reacted only with the recombinant polycystin fragment containing the respective peptide used in immunization.

\section{Molecular Mass of Polycystin}

Western blotting was performed on extracts from rat adult brain tissue and kidney-containing hemisections of rat fetuses (gestational age 18 days), using the two anti-peptide antibodies. For these experiments, fresh rat tissues were harvested and used immediately to minimize proteolysis. In rat brain tissues, AP2 recognized three

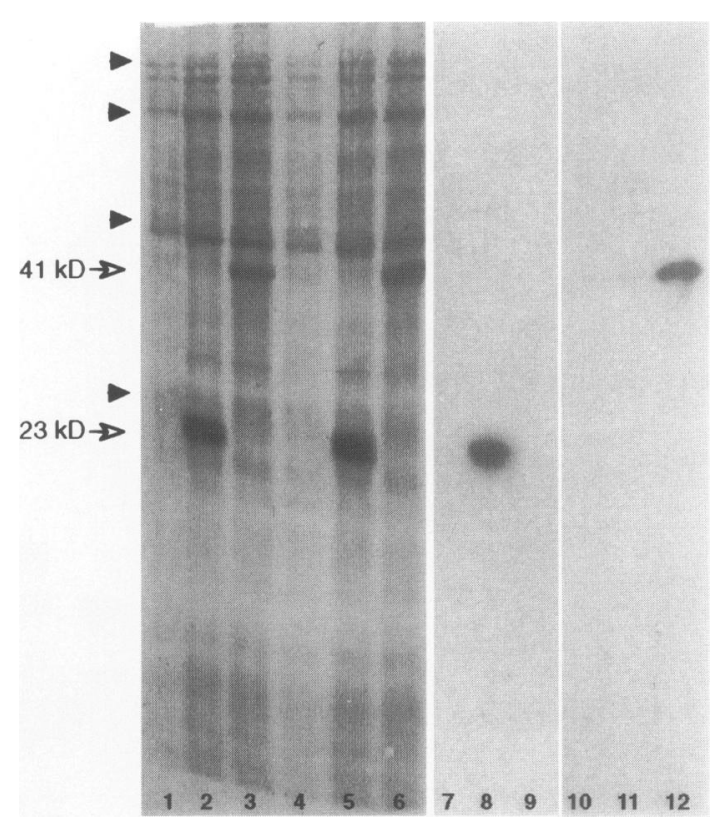

FIG. 1. Expression of recombinant polycystin fusion peptides

(left panel) Coomassie stain of a 14\% SDS-polyacrylamide gel following electrophoresis of lysates from IPTG-induced E. coli transformed with vector alone (control, Lanes 1 and 4) or with plasmids containing the 527-bp (Lanes 2 and 5) and 851-bp (Lanes 3 and 6) polycystin cDNA fragments. Prominent Coomassiestained bands of $\sim 23 \mathrm{kD}$ (Lanes 2 and 5) and $\sim 41$ $\mathrm{kD}$ (Lanes 3 and 6) are detected. These bands are not seen in the control (Lanes 1 and 4). (right panel) Western blotting of a gel similar to the one shown in the left panel, probed with AP2 (Lanes 7-9) or AP1 (Lanes 10-12). AP1 and AP2 reacted with the $4 \mathrm{l}-$ and the $23-\mathrm{kD}$ fusion proteins, respectively. Arrowheads represent mobility of the molecular mass markers from Gibco-BRL: phosphorylase $b$ (125.6 kD), bovine serum albumin (79.6 kD), ovalbumin $(47.7 \mathrm{kD})$, and carbonic anhydrase (28.1 kD).

major bands at 642, 405, and $239 \mathrm{kD}$ (Fig. 2, Lane 1). These bands were competed in the presence of P2 (data not shown). In rat fetal kidneycontaining hemisections, two major specific bands at 415 and $239 \mathrm{kD}$ were seen. In addition, fainter bands at 139 and $211 \mathrm{kD}$, and a variable band at $312 \mathrm{kD}$ were observed (Fig. 2, Lanes 2 and 3). These bands disappeared in the presence of the P2 peptide (Fig. 2, Lane 4). The 415- and 211-kD species were also visualized with APl (Fig. 2, Lane 6). The faintness of the $415-\mathrm{kD}$ band detected with APl may reflect inadequate renaturation of the internal PI epitope in the highmolecular weight forms of polycystin. In rat fetal kidney tissue, APl also reacted with three additional bands of about 271, 194, and 109 kD (Fig. 2, 


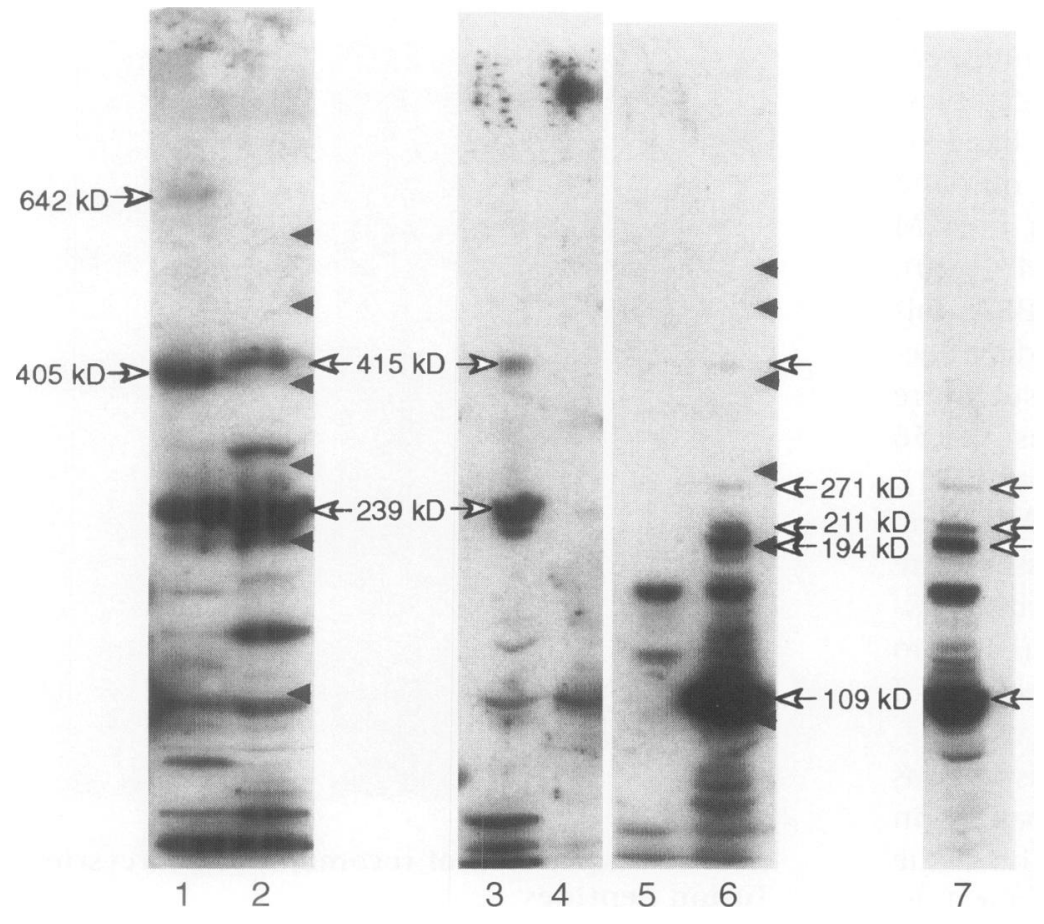

FIG. 2. Western blotting of rat and human fetal kidney tissues using AP1 and AP2

Extracts from rat brain (Lane 1) and rat fetal kidney-containing tissue (Lane 2) probed with AP2. The major bands are indicated by arrows. Lanes 3-6, a second experiment where the electrophoresed extracts from rat fetal tissues were probed with AP2 (Lanes 3 and 4) or APl (Lanes 5 and 6) in the absence (Lanes 3 and 6) or presence (Lanes 4 and 5) of the respective peptide. The high-molecular mass bands that are competed when the peptide is present are indicated by arrows. The major specific bands detected by APl in the rat tissues are also seen in human fetal kidney tissue (Lane 7, arrows), and are competed by the respective peptide in this species (data not shown). The cross-linked phosphorylase $b$ SDS molecular weight markers of $584.4,487.0,389.6,292.2,194.8$, and $97.4 \mathrm{kD}$ (obtained from Sigma) are indicated by arrowheads.
Lane 6). The last band was also detected in SDSextracted "matrix" present on tissue culture plates after detachment of subconfluent monolayers of human HT29 colonic tumor cells (provided by Daniel Podolsky, MGH), suggesting that this product is released from cells (data not shown). The 271-, 194-, and 109-kD bands were not detected by AP2 (Fig. 2, Lanes 2 and 3), suggesting that they do not contain the C-terminal portion of polycystin. APl gave a strikingly similar protein profile when human fetal kidney tissue was analyzed (Fig. 2, compare Lane 7 with Lane 6). Taken together, these findings indicate that the largest form of polycystin has an apparent molecular mass of $642 \mathrm{kD}$. The absence of this species in kidney tissue processed under identical conditions may reflect either tissue-specific expression of this form of polycystin or perhaps a greater intrinsic proteolytic activity in peripheral tissues. Tissue-specific alternative splicing or proteolysis and differential glycosylation may also be important in generation of some of the specific lower molecular mass forms.

\section{Immunolocalization of Polycystin in Normal Rat and Human Kidneys}

In frozen sections of rat fetal kidney, APl reacted strongly with the basal surface and weakly with the apical pole of the branching ureteric bud and collecting duct epithelium (Fig. 3a). There was weak staining of the basal surface of S-shaped (Fig. 3a) and comma-shaped bodies (not shown), and of developing proximal tubules (Fig. 3a and data not shown). In developing glomeruli, there was heavy staining at the level of the basement membrane and weak staining of Bowman's capsule (Fig. 3a). All this staining was completely blocked by $\mathrm{Pl}$ (not shown). No staining of uninduced mesenchyme, interstitium, or vasculature was observed. In frozen sections of human fetal kidneys, AP1 revealed moderate staining of the apical surface of cortical collecting ducts (Fig. 3b) and ureteric buds (not shown), but weak staining at their basolateral surfaces. The nature of these structures was confirmed by positive staining with FITC-conjugated DBA (data not shown). There was intense staining of developing glomeruli at the level of the basement membrane (Fig. 3b), identical to that seen in rat fetal kidneys. Examination by confocal microscopy showed the staining to be associated with the basolateral membrane of visceral epithelial cells (not shown). Faint staining was observed in the apical and lateral surfaces of parietal epithelium (Fig. 3b, and data not shown). In all cases, staining was abolished in the presence of the Pl peptide (data not shown). AP2 did not result in any staining in rat or human tissues under these standard conditions. However, when these tissues were denatured with $6 \mathrm{M}$ urea, specific staining of collecting duct epithelium was seen (Fig. 3c and data not shown).

Polycystin was also detected, albeit in lower 

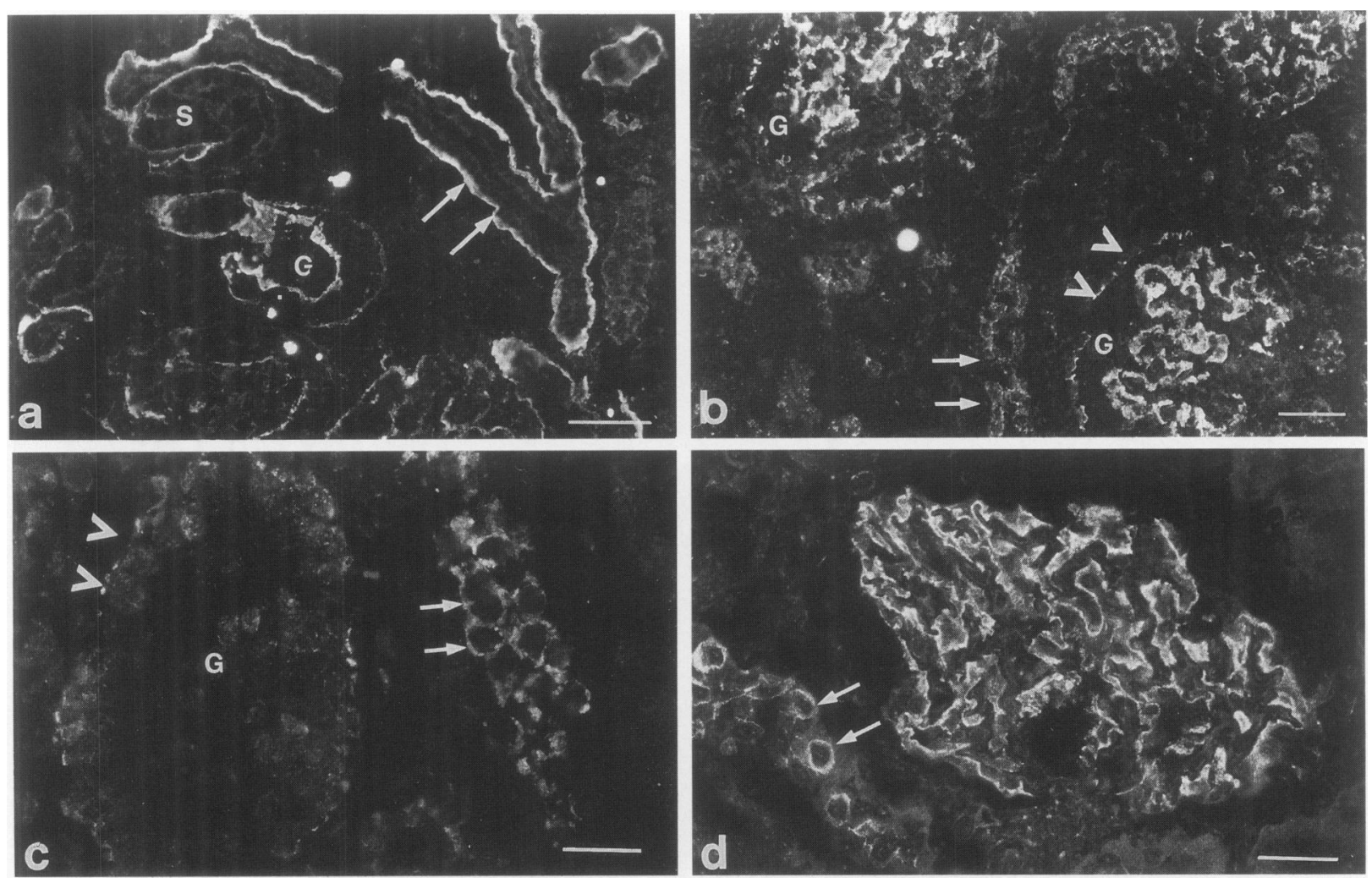

FIG. 3. Immunolocalization of polycystin in rat fetal kidney (18 day gestation) (a), human fetal kidney (12 week gestation) (b and c), and human adult kidney (d)

Staining was carried out using AP1 (a, b, and d) and AP2 (c). (a) Branching ureteric buds are stained brightly at the basal surface (arrow), and faintly at the apical surface. Bright staining is observed in developing glomeruli (G), at the level of the glomerular basement membrane, with weak staining of Bowman's capsule. Moderate staining of an S-shaped body (S) is also seen. Bar $=20 \mu \mathrm{m}$. (b) Intense staining of human fetal glomeruli (G) at the level of the basement membrane, with occasional staining of parietal epithelium and moderate staining of the apical pole (arrows) of a collecting duct. Bar $=20 \mu \mathrm{m}$. (c) AP2 staining of parietal epithelium but not the glomerular tuft, and moderate staining (arrows) of a collecting duct. The tissue was first denatured with $6 \mathrm{M}$ urea prior to staining. Bar $=20 \mu \mathrm{m}$. (d) Bright staining at the level of the basement membrane of a glomerulus, but no staining of Bowman's capsule. Moderate apical and basolateral staining of intercalated cells (arrows) is also observed. Bar $=20$ $\mu \mathrm{m}$.

amounts, in glomeruli and collecting ducts of frozen sections from normal human adult kidney tissue. In glomeruli, linear staining was seen at the level of the basement membrane. In collecting ducts (identified by their positive staining with DBA), APl stained the apical and the basolateral surface of epithelial cells (Fig. 3d). This staining was limited to intercalated cells (expressing the $56-\mathrm{kD}$ subunit of $\mathrm{H}^{+}$-ATPase, not shown). The glomerular and collecting duct staining was again blocked by the Pl peptide (not shown). No labeling was seen in other urinary tubules, in the interstitium, or in the vasculature. Staining of sections from formalin-fixed, paraffinembedded normal human adult kidney tissue with AP1 revealed widespread nonspecific staining of tubular epithelium (not blocked by P1, data not shown). Similarly, minimal staining with APl was seen in formalin-fixed, paraffin-embedded human fetal kidney (20-week gestation). These data suggest that formalin fixation impairs the reactivity of APl with its antigen and increases background staining by this antibody in healthy renal tissue.

\section{Abnormal Cellular Localization of Polycystin in ADPKD Kidneys}

In sections of freshly frozen end-stage kidney tissue from two patients with ADPKD, API produced strong and specific staining of cyst-lining epithelia (Fig. 4 a-c) as well as in noncystic tubules (not shown). A similar pattern was seen in denatured ADPKD kidney tissue using AP2 (Fig. 4d). Little staining was observed in glomer- 

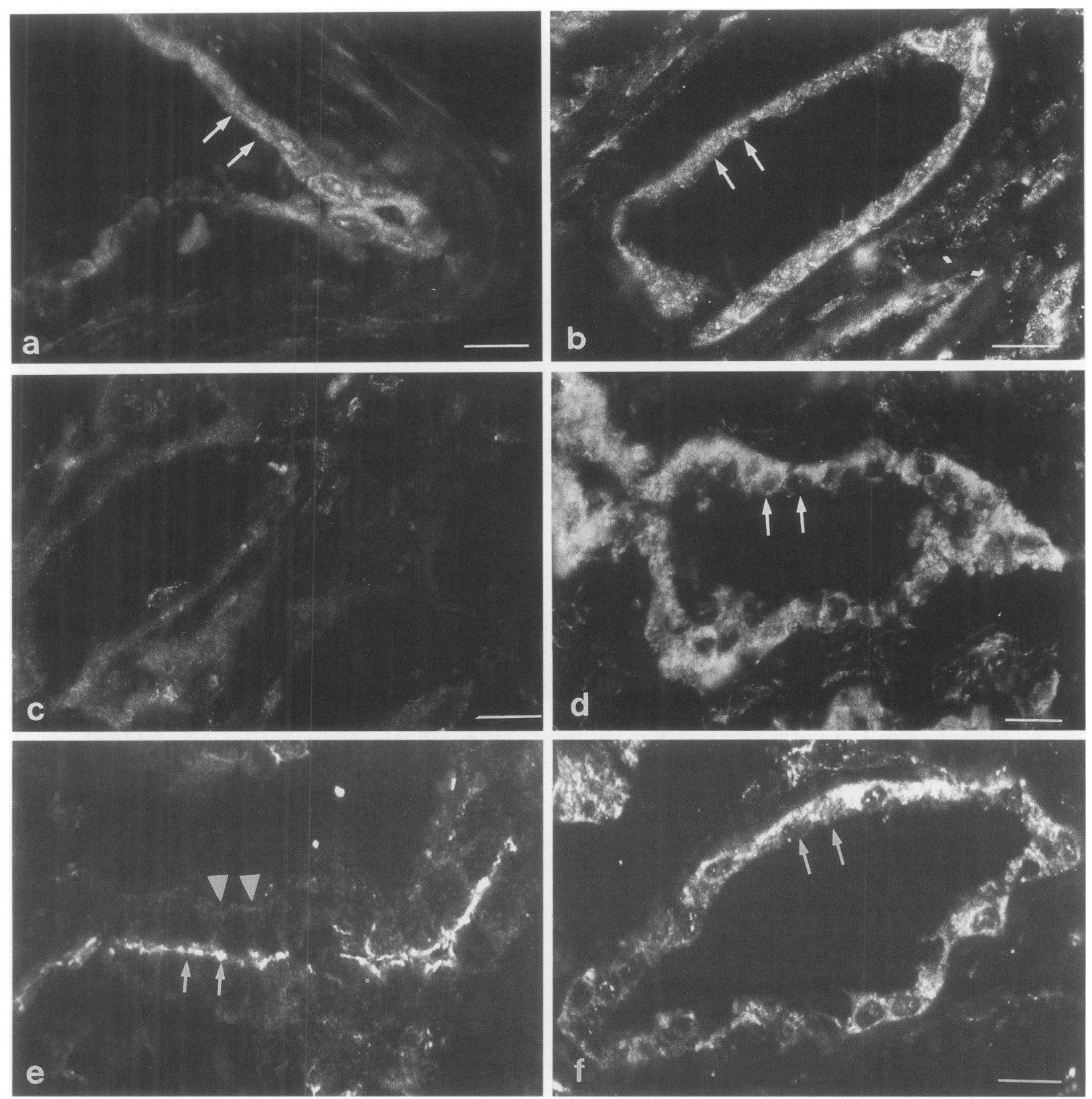

\section{FIG. 4. Immunolocalization of polycystin in kidneys from two patients with ADPKD}

APl (a, b, c, e, and f) and AP-2 (d) were used for immunostaining. (a-d) There is intense cytoplasmic staining of the epithelial cells of cystic tubules (arrows) in Patient $l$ (a) and 2 (b and c). Staining was largely abolished in the presence of $\mathrm{Pl}$ (c). Bar $=20 \mu \mathrm{m}$. (e and f) Confocal microscopy images of tissue sections from normal human fetal kidney (e) and ADPKD kidney from Patient 2 (f) are shown. The strong apical (arrows) and weak basal (arrow heads) staining in normal epithelium is replaced by heavy cytoplasmic staining in the cyst-lining epithelial cells (d, arrows), that is most intense in the preinuclear region. Bar $=20 \mu \mathrm{m}$.

uli, which were largely sclerosed (not shown). In contrast to normal tissues, most of the staining in cystic epithelium from fresh frozen tissue was intracellular (Fig. 4 a and b). This was confirmed by examining APl-stained normal and cyst-lining epithelium by confocal microscopy (Fig. $4 \mathrm{e}$ and f). While polycystin was associated with the surface membrane in normal human fetal collecting duct epithelium, it was largely cytoplasmic in ADPKD cyst-lining epithelium and was clustered and most intense in the perinuclear area (Fig. 4f). 


\section{DISCUSSION}

The major findings in the present report are the following. First, we have identified a $642-\mathrm{kD}$ form of polycystin. This is considerably higher than the predicted $462-\mathrm{kD}$ size for the unmodified protein, suggesting that polycystin may be heavily glycosylated. Second, polycystin exhibits cell surface as well as basement membrane distributions, suggesting the presence of membrane-associated and secreted forms of this protein. Third, one form of polycystin presumably lacking the C-terminal cytoplasmic region is present basolaterally in human and rat glomerular visceral epithelium. Fourth, although expression of polycystin is increased in ADPKD cyst-lining kidney epithelium, its subcellular localization is abnormal, being largely restricted to the cell cytoplasm.

Evidence that the immunoreactivity of APl and AP2 represents the identification of polycystin in rat and human tissues is based on the following observations. First, affinity-purified anti-peptide antibodies were used that recognize specific polycystin-derived recombinant fusion proteins (Fig. 1) and are directed against highly conserved epitopes in human and rodent polycystin. Both peptides also lie outside the region that is homologous with the recently cloned PKD2 protein (23). Second, both antibodies reacted with collecting duct epithelium and demonstrated strong reactivity with cyst-lining ADPKD epithelium, which agrees with previous reports $(13,24)$. Third, the collecting duct staining patterns clearly differed between developing and mature renal tissues, consistent with other data showing that expression of PKDl is developmentally regulated $(12,24)$. Fourth, the observed immunoreactivity in tissues is also consistent with one form of polycystin being membraneassociated, with a readily accessible P1 peptide and a presumed intracellular P2 peptide that is exposed only after tissue denaturation.

In humans, but not in rodents, a major part of PKDl is duplicated, and the duplicated area appears to encode three genes that share substantial homology with PKDl $(12,15)$. Each of these genes produces a polyadenylated transcript, and all have conserved 3' regions that differ from PKDl. The pattern of reactivity of APl, which recognizes a peptide encoded by the duplicated segment of human PKDl, was strikingly similar in both rat and human fetal kidney tissues (Fig. 2, Lanes 6 and 7). One interpretation of this finding is that the PKDl homolog tran- scripts are not translated into proteins in humans. Alternatively, the protein homologs may be present in amounts too small to be detectable or are expressed in other tissues not examined here.

In rat and human fetal kidneys, polycystin was abundantly expressed basolaterally and apically in ureteric bud and collecting tubule epithelia, and basolaterally in the visceral epithelium of developing glomeruli (Fig. 3). It was weakly expressed in glomerular parietal epithelium. The prominent basolateral staining observed in some sections (Fig. 3a) and in rat skin (not shown) suggests that some component of polycystin is released from the cell surface, as shown in HT29 cells. In human adult kidneys, polycystin was still detectable in glomeruli and prominent in the intercalated cells of collecting ducts. Strong expression of polycystin in fetal renal tubular epithelium has also been found in two recent studies $(13,24)$. Ward et al. have used two monoclonal antibodies (mAbs) raised against a fusion protein to show that polycystin is expressed in epithelial cells of cortical tubules and ureteric buds in human fetal kidneys, with some staining of the parietal epithelium in Bowman's capsule (13). Griffin et al. (24), using anti-peptide antibodies from the putative cytoplasmic region, also found staining in fetal human renal cortical tubular epithelium. Griffin et al., however, did not find staining in adult human kidney, in contrast to the data by Ward et al., who found that strong staining persisted in cortical tubules of adult kidney. Our data show a significant reduction in tubular staining of adult human kidney, which is largely limited to the intercalated cells. We find, in addition, that one form of polycystin is expressed in fetal and adult visceral glomerular epithelium. In our study, staining of the visceral epithelium was observed using only API (recognizing an epitope in the ectodomain), not the cytoplasmic-directed antibody, AP2. The differences observed could thus be a function of the antibodies used. The two mAbs used by Ward et al. and the two anti-peptide antibodies utilized by Griffin et al. were raised against epitopes contained in the C-terminal 1225 aa of polycystin, and thus do not include the Pl epitope. The staining observed on the basal surface of the human glomerular visceral epithelium is not likely to be caused by reactivity of API with a polycystin homologue, since an identical staining pattern was also observed in the rat. The presence of a $109-\mathrm{kD}$ form of polycystin in the matrix deposited by HT29 cells suggests that one form of polycystin may be 
associated with basement membranes. While the detection of polycystin in cortical tubules provides a histologic basis for the early involvement of cortical tubules in ADPKD, the significance of polycystin expression in glomeruli is unclear at present, since primary glomerular abnormalities are generally lacking in ADPKD. Griffin et al. (24) also observed strong staining of human fetal cells from neural crest origin, although defects in the respective organs (adrenal medulla, intestinal neural plexuses) are not recognized features of ADPKDI. Adaptive changes may help compensate for the deficiency of polycystin in certain tissues.

In normal fetal and adult collecting ducts, polycystin displayed a cell surface-associated distribution (Fig. 3), consistent with its predicted membrane-spanning regions $(14,15)$. In developing rat kidney, intense staining was observed basolaterally in ureteric buds, whereas apical staining of this tissue was predominant in human fetal kidney. This difference may reflect species differences and/or redistribution of the antigen secondary to the unavoidable delay in processing of human fetal tissue. The primary sequence of polycystin reveals several domains known to mediate cell-cell and cell matrix adhesion in other proteins. The basolateral distribution of polycystin in normal collecting duct epithelium supports a putative cell-matrix adhesion function(s) for this protein in epithelia. Its apical distribution does not exclude a role for polycystin in adhesion, since some adhesion proteins may be expressed apically in epithelia under certain conditions (25-27). Polycystin may also serve a transport function in apical membranes, a role suggested recently by the significant homology of the C-terminal region of polycystin to the PKD2 protein and to a voltage-activated sodium channel (23). These putative functions are probably not essential for epithelial development, since formation of kidneys is initially normal in ADPKD, but may be essential in the maintenance and remodeling of already formed epithelium.

Expression of polycystin was increased in the epithelial lining of renal cysts in ADPKD. This observation agrees with that recently reported by Ward et al. and Griffin et al. $(13,24)$ in patients with ADPKD1 (but not ADPKD2 or acquired renal cystic disease). Significantly, we found that polycystin was largely cytoplasmic in the epithelial lining of cysts (Fig. 4), in contrast to its predominantly surface membrane-associated localization in normal fetal and adult kidney epithelium (Fig. 3). Ward et al. has shown that in ADPKD increased quantities of the wild-type as well as the mutant alleles are expressed (13). The minimal surface expression of polycystin in ADPKD cyst-lining epithelium suggests, therefore, that the normal allele is unable to reach the cell surface in sufficient amounts to mediate its functions. Functional loss of polycystin from the cell surface may therefore be a likely mechanism by which mutations in the PKDl gene cause disease, at least in some patients. Formation of a nonfunctional complex between the wild-type and mutant alleles may be one mechanism for deficient surface expression. The cyst-lining epithelium in ADPKD expresses embryonic genes and proteins. It also displays a reversed polarity of several of its membrane proteins and a delay in the exit of some surface components from the Golgi $(18,28)$. These alterations may involve interactions of the mutant polycystin with as yet uncharacterized intracellular proteins.

\section{ACKNOWLEDGMENTS}

RP and CPS contributed equally to this work. We thank Ms. Colleen Loiselle for secretarial help and Dr. Anna-Maria Frischauf for providing the mouse polycystin sequence corresponding to P1. Part of this work was presented at the 28th annual meeting of the American Society of Nephrology in November 1995. This work was supported by the National Institutes of Health (DK51051) and a Physician-Investigator fellowship grant to RP from the American Heart Association, Mass. Affiliate.

\section{REFERENCES}

1. Dalgaard OZ. (1957) Bilateral polycystic disease of the kidneys: A follow up of two hundred and eighty-four patients and their families. Acta Med. Scand. Suppl. 328: 1-255.

2. Gabow PA. (1993) Autosomal dominant polycystic kidney disease. N. Engl. J. Med. 329: 332-342. Review.

3. Parfrey PS, Bear JC, Morgan J, et al. (1990) The diagnosis and prognosis of autosomal dominant polycystic kidney disease. $N$. Engl. J. Med. 323: 1085-1090.

4. Reeders ST, Breuning MH, Davies KE, et al. (1985) A highly polymorphic DNA marker linked to adult polcystic kidney disease on chromosome 16. Nature 317: 542-544.

5. Kimberling WJ, Kumar S, Gabow PA, Kenyon JB, Conolly CJ, Somlo S. (1993) Autosomal dominant polycystic kidney disease: 
Localization of the second gene to chromosome 4q13-q23. Genomics 18: 467-472.

6. Peters DJ, Spruit L, Saris JJ, et al. (1993) Chromosome 4 localization of a second gene for autosomal dominantpolycystic kidney disease. Nat. Genet. 5: 359-362.

7. Fossdal R, Bothvarsson $M$, Asmundsson $P$, et al. (1993) Icelandic families with autosomal dominant polycystic kidney disease: Families unlinked to chromosome $16 \mathrm{p} 13.3$ revealed by linkage analysis. Hum. Genet. 91: 609-613.

8. Daoust MC, Reynolds DM, Bichet DG, Somlo S. (1995) Evidence for a third genetic locus for autosomal dominant polycystic kidney disease. Genomics 25: 733-736.

9. Gabow PA, Johnson AM, Kaehny WD, et al. (1992) Factors affecting the progression of renal disease in autosomal-dominant polycystic kidney disease. Kidney Int. 41: 1311-1319.

10. Elgar G, Sandford R, Aparicio S, Macrae A, Venkatesh BS, Brenner S. (1996) Small is beautiful: Comparatuive genomics wioth the pufferfish (Fugu rubribes). Trends Genet. 12: 145-150.

11. Wilkinson-Sproat J. (1995) ZK945.9; Swiss/ Q09624-EMBL/GENBANK/DDBJ DATA BANKS.

12. Consortium, European Polycystic Kidney Disease. (1994) The polycystic kidney disease 1 gene encodes a $14 \mathrm{~kb}$ transcript and lies within a dublicated region on chromosome 16. Cell 77: 881-894.

13. Ward CJ, Turley H, Ong AC, et al. (1996) Polycystin, the polycystic kidney disease 1 protein, is expressed by epithelial cells in fetal, adult, and plocystic kidney. Proc. Natl. Acad. Sci. U.S.A. 93: 1524-1528.

14. Consortium, The International Polycystic Kidney Disease. (1995) Polycystic kidney disease: The complete structure of the PKD 1 gene and its protein. Cell 81: 289-298.

15. Hughes J, Ward CJ, Belen P, et al. (1995) The polycystic kidney disease 1 (PKDl) gene encodes a novel protein with multiple cell recognition domains. Nature Genet. 10: 151-161.

16. Cuppage FE, Huseman RA, Chapman A, Grantheam JJ. (1980) Ultrastructure and function of cysts from human adult polycystic kidneys. Kidney Int. 17: 372-381.

17. Falkenstein D, Burrow CR, Gatti L, Hartz P, Wilson PD. (1993) Expression of fetal proteins in human polycystic kidney disease (PKD) epithelia (abstract). J. Am. Soc. Nephrol. 3: 813.

18. Carone FA, Bacallao R, Kanwar YS. (1994) Biology of polycystic kidney disease. Lab. Invest. 70: 437-448. Review.

19. Laemmli UK. (1970) Cleavage of structural proteins during the assembly of the head of bacteriophage T4. Nature 227: 680-685.

20. Peissel B, Geng L, Kalluri R, et al. (1995) Comparative distribution of the al(IV), and a6(IV) collagen chains in normal human adult and fetal tissues and in kidneys from X-linked Alport Syndrome patients. J. Clin. Invest. 96: 1948-1957.

21. Nelson RD, Guo X-L, Masood K, Brown D, Kalkbrenner M, Gluck S. (1992) Selectively amplified expression of an isoform of the vaculoral $\mathrm{H}^{+}$-ATPase 56 kilodalton subunit in renal intercalated cells. Proc. Natl. Acad. Sci. U.S.A. 89: 3541-3545.

22. Holthofer H, Virtanen I, Pettersson E, et al. (1981) Lectins as fluorescence microscopic markers for saccharides in the human kidney. Lab. Invest. 45: 391-399.

23. Mochizuki T, Wu G, Hayashi T, et al. (1996) PKD2, a gene for polycystic kidney disease that encodes an integral membrane protein. Science 272: 1339-1342.

24. Griffin MD, Torres VE, Grande JP, Kumar R. (1996) Immunolocalization of polycystin in human tissues and cultured cells. Proc. Assoc. Am. Physcians 3: 185-197.

25. Bernfield MR, Kokenyesi R, Kato M, et al. (1992) Biology of the syndecans: a family of transmembrane heparan sulphate proteoglycans. Annu. Rev. Cell Biol. 8: 365-393.

26. Goligorsky MS, Lieberthal W, Racusen L, Simon EE. (1993) Integrin receptors in renal tubular epithelium: New insights into pathophysiology of acute renal failure. Am. J. Physiol. 264: Fl-F8.

27. Arnaout MA. (1995) Structure and regulation of cell adhesion molecules. In: Frank MM, Austen KF, Claman HN, Unanue ER (eds). Samter's Immunologic Diseases. Little, Brown, Boston, pp. 161-182.

28. Grantham JJ. (1993) Polycystic kidney disease: Hereditary and acquired. $A d v$. Int. Med. 38: 409-420. Review.

Contributed by R. Cotran. Accepted on August 16, 1996. 